\title{
Os vinte anos da Revista Ensaio analisados por meio de Redes Sociais
}

\author{
Alvaro Chrispino $^{a}$ \\ Marcia Bengio Albuquerque ${ }^{a}$ \\ Patricia Borges Coutinho da Silva ${ }^{a}$
}

\section{Resumo}

A proposta deste trabalho é apresentar os 20 anos de história da Revista Ensaio, utilizando-se a abordagem de Redes Sociais, mais especificamente a partir da aplicação do software PAJEK. Para alcançar tal objetivo, foram listados todos os artigos publicados nos 80 números que compõem o período, registrando autor(es), instituição a que se vincula o autor e palavras-chave. Para melhor compreensão, além da análise completa dos 20 anos, usaram-se, como categoria de análise, a primeira e a segunda décadas, permitindo uma visão de evolução. Foram listados 620 artigos, 1.325 autores e 1.131 palavras-chave. A primeira análise dos dados resultou em lista (Top Ten) dos autores que mais publicaram, das instituições mais representadas e das palavras-chave mais utilizadas por década. Note-se que, no total, demonstrou-se que a Ensaio cumpre sua missão, conforme definição no momento de sua criação.

Palavras-chave: Revista Ensaio. Editoração científica. Redes sociais.

\section{Introdução}

A Revista Ensaio: Avaliação e Políticas Públicas em Educação foi criada em 1993 e, desde então, circula de forma ininterrupta e periodicamente, o que, antecipadamente, já seria um marco no espaço editorial brasileiro, frente às dificuldades que todos conhecemos e enfrentamos na área.

No Editorial do primeiro número, da lavra de Carlos Alberto Serpa de Oliveira, o primeiro Editor, é possível identificar sua proposta de ação quando lemos:

\footnotetext{
a Centro Federal de Educação Tecnológica Celso Suckow da Fonseca - CEFET/RJ, Rio de Janeiro, Rio de Janeiro, Brasil
} 
"Concedemos à avaliação, [...], amplitude maior, que não a associa, com singularidade, de forma excludente, ao ensinoaprendizagem. Mas ao contrário, empresta-lhe perspectivas de um horizonte mais largo, como, a propósito, as políticas públicas em educação e aos aspectos organizacionais dos sistemas e instituições educacionais" (OLIVEIRA, 1993, grifo nosso).

Recebeu conceito nacional "A" na avaliação dos Periódicos Científicos em Educação, realizada em 2001 pelo Qualis/CNPq, o que demonstra o reconhecimento da área de Educação.

No ano de 2005, a Ensaio é admitida no Scielo, quando informa que sua missão é "divulgar pesquisas, levantamentos, estudos, discussões e outros trabalhos críticos no campo da educação, concentrando-se nas questões de avaliação e políticas públicas, e enfatizando as experiências e perspectivas brasileiras" (grifos nossos). A partir daí, a Revista passa a oferecer consulta eletrônica, ampliando sua capilaridade e potencial de divulgação. As ferramentas estatísticas disponíveis no Scielo permitem muitas inferências sobre a visitação e o impacto do periódico e dos artigos. Para o propósito deste trabalho, listamos os dez trabalhos mais acessados no site no Quadro 1 abaixo:

A Revista Ensaio, que tem contribuído de forma relevante para as discussões sobre avaliação no campo educacional brasileiro, também tem alcançado realce no campo das políticas públicas. Faria (2012), em importante levantamento sobre as Políticas Públicas no Brasil, pesquisando sobre os periódicos nacionais que tratam de Políticas Públicas, conclui que "no WebQualis, da Capes, há listados 19 periódicos desta natureza (...). Porém, apenas um deles (Ensaio: Avaliação e Políticas Públicas em Educação) encontrava-se, em setembro de 2011, entre os periódicos do Scielo Brasil.” (FARIA, 2012, p. 126).

Outro trabalho, de alguma forma, trouxe informe e reflexões importantes para o desenho dos temas divulgados pela Ensaio, e aponta possíveis lacunas temáticas nos campos aos quais se dedica o periódico. Tavares, Oliveira e Seiffert (2011) buscaram sintetizar as produções da Ensaio, em recortes e metodologias distintas, nos quais "analisa as ênfases e tendências dos textos publicados pela Revista Ensaio: avaliação e políticas públicas em educação, tomando como referência a política de avaliação para a educação superior" nas eras FHC e Lula. Informam que a Ensaio "poderia conter mais discussões sobre avaliação da educação superior. Chama atenção a quase ausência de textos sobre o Conceito Preliminar de Cursos 
Quadro 1 - Os dez trabalhos mais acessados da revista Ensaio através do site scielo.br

\begin{tabular}{|c|c|c|}
\hline$N$ & $\begin{array}{l}\mathrm{N} \text { de } \\
\text { acessos }\end{array}$ & Artigo \\
\hline 1 & 26210 & $\begin{array}{l}\text { SANTOS, Sônia Querino dos Santos e MACHADO, Vera Lúcia de Carvalho. } \\
\text { Políticas públicas educacionais: antigas reivindicações, conquistas (Lei } \\
\text { 10.639) e novos desafios. Ensaio: aval. pol. públ. Educ., 2008, vol.16, n. }{ }^{50} \text {, } \\
\text { p.95-112. ISSN 0104-4036. }\end{array}$ \\
\hline 2 & 26077 & 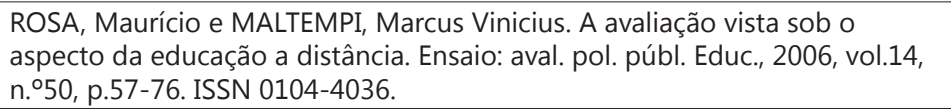 \\
\hline 3 & 25809 & 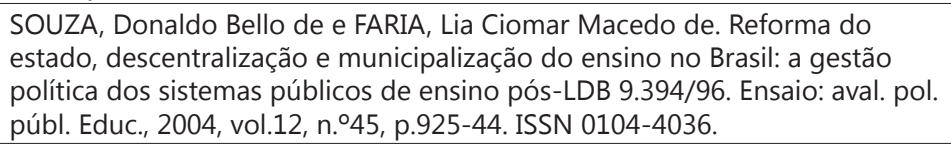 \\
\hline 4 & 24796 & $\begin{array}{l}\text { GOHN, Maria da Glória. Educação não-formal, participação da sociedade } \\
\text { civil e estruturas colegiadas nas escolas. Ensaio: aval. pol. públ. Educ., 2006, } \\
\text { vol.14, n. }{ }^{50} \text {, p.27-38. ISSN 0104-4036. }\end{array}$ \\
\hline 5 & 22544 & $\begin{array}{l}\text { OLIVEIRA, Anna Augusta Sampaio de e LEITE, Lucia Pereira. Construção de } \\
\text { um sistema educacional inclusivo: um desafio político-pedagógico. Ensaio: } \\
\text { aval. pol. públ. Educ., 2007, vol.15, n. } 57 \text {, p.511-24. ISSN 0104-4036. }\end{array}$ \\
\hline 6 & 22111 & $\begin{array}{l}\text { FRIEDRICH, Márcia; BENITE, Anna M. Canavarro; BENITE, Claudio R. Macha- } \\
\text { do et al. Trajetória da escolarização de jovens e adultos no Brasil: de platafor- } \\
\text { mas de governo a propostas pedagógicas esvaziadas. Ensaio: aval. pol. públ. } \\
\text { Educ., 2010, vol.18, n. }{ }^{\circ} 67, \text { p.389-410. ISSN 0104-4036. }\end{array}$ \\
\hline 7 & 20050 & $\begin{array}{l}\text { OLIVEIRA, João Batista Araujo e. Avaliação em alfabetização. Ensaio: aval. pol. } \\
\text { públ. Educ., 2005, vol.13, n. }{ }^{\circ 48, ~ p .375-82 . ~ I S S N ~ 0104-4036 . ~}\end{array}$ \\
\hline 8 & 19648 & $\begin{array}{l}\text { SILVA, Rosenir Rita de Cássia Moreira da, MAINIER, Fernando Benedicto e } \\
\text { PASSOS, Fabio Barboza. A contribuição da disciplina de introdução à engen- } \\
\text { haria química no diagnóstico da evasão. Ensaio: aval. pol. públ. Educ., 2006, } \\
\text { vol.14, n. }{ }^{\circ 51, ~ p .261-77 . ~ I S S N ~ 0104-4036 . ~}\end{array}$ \\
\hline 9 & 18845 & $\begin{array}{l}\text { CHRISPINO, Álvaro. Gestão do conflito escolar: da classificação dos conflitos } \\
\text { aos modelos de mediação. Ensaio: aval. pol. públ. Educ., 2007, vol.15, n. }{ }^{\circ} 54, \\
\text { p.11-28. ISSN 0104-4036. }\end{array}$ \\
\hline 10 & 18810 & $\begin{array}{l}\text { OLIVEIRA, Marcos Marques de. As origens da educação no Brasil da hege- } \\
\text { monia católica às primeiras tentativas de organização do ensino. Ensaio: aval. } \\
\text { pol. públ. Educ., 2004, vol.12, n. }{ }^{\circ} 45, \text { p.945-58. ISSN 0104-4036. }\end{array}$ \\
\hline
\end{tabular}

Fonte: o autor, a partir de Scielo.br (2014).

(CPC) e o Índice Geral de Cursos (IGC) criados em 2008, e que modificaram a concepção original do SINAES". Em suas conclusões, escrevem:

"Por fim, ressalta-se a importância desse periódico enquanto espaço de socialização dos estudos sobre avaliação da educação, especialmente da educação superior, destacando que a ênfase/ tendência dos textos publicados contém a ideia da avaliação como desempenho e avaliação associada à qualidade da educação." 
O presente trabalho é uma pesquisa bibliográfica que listou todos os artigos da Ensaio ao longo de vinte anos, identificando autores, instituições a que estão vinculados e palavras-chave utilizadas, buscando conhecer o perfil dos autores, o tipo de instituição e os temas mais referenciados ao longo das décadas. Realizou-se este levantamento e se utilizou, para a apresentação dos resultados, de software de redes sociais. Os resultados aqui expostos são as primeiras possibilidades de análise.

\section{Usando redes sociais como ferramenta}

A definição de redes sociais está longe de ser consensual. Os primeiros conceitos surgem na década de 1940 e daí derivam suas propriedades na multiplicidade das relações sociais. Barnes (1987) foi um dos pioneiros na utilização do termo, abordando padrões de fios e seus entrelaçamentos, acoplado aos conceitos das Ciências Sociais, quando propõe o uso de redes para análise e descrição de processos sociais que envolvem conexões que vão além dos limites de grupos e categorias. (CHRISPINO et al., 2013; CHRISPINO; LIMA; ALBUQUERQUE, 2013).

É possível encontrar duas grandes abordagens no universo das redes sociais: o metafórico e o analítico. Mitchell (1996 apud SCOTT, 2004) propõe conciliar as duas abordagens, pois ambas, isoladamente, possuem limitações. Enquanto, na metáfora, a noção de rede não permite a percepção de aspectos das relações sociais, a abordagem analítica limitaria a representação pessoal em linhas e nós de rede. Baseando-se na matemática da Teoria de Grafos, esta se agregou à pesquisa de base sociológica visando a esclarecer as propriedades estruturais das organizações sociais. A maneira viva como se processam as inter-relações nas redes sociais sugere uma abordagem complexa e inclusiva. Para tal, todas as nuances e possibilidades de comunicação podem e devem ser consideradas, constituindo, assim, um ambiente dinâmico de múltiplas relações, que só adquirem significado total quando se contempla sua completude.

Uma metáfora apresentada por Elias (1994, p. 35) deixa claro que

[...] para ter uma visão mais detalhada desse tipo de inter-relação, podemos pensar no objeto de que deriva o conceito de rede: a rede de tecido. Nessa rede, muitos fios isolados ligam-se uns aos outros. No entanto, nem a totalidade da rede nem a forma assumida por cada um de seus fios podem ser compreendidas em 
termos de um único fio, ou mesmo de todos eles, isoladamente considerados; a rede só é compreensível em termos da maneira como eles se ligam, de sua relação recíproca.

Para este trabalho, utilizaremos os graus de entrada (citação) para autores, palavras-chave e instituições a que se vinculam os autores, indicando para trabalhos futuros, com o mesmo banco de dados, outras possibilidades disponíveis com a abordagem de Redes Sociais. ${ }^{1}$

\subsection{Metodologia}

\section{O estudo pesquisou 466 artigos ao longo de vinte anos.}

\section{Como restrição de pesquisa, temos o fato de que, especialmente na primeira década, no período de implantação, houve a publicação de documentos e relatórios próprios da área, e de interesse dos leitores da Ensaio. Estes documentos e}

\footnotetext{
1 Para maior entendimento sobre Redes Sociais, reproduzimos Chrispino et al. (2013): Conceitos básicos em redes

"Uma rede, que pode ser modelada por um grafo, é definida como um conjunto de vértices ou atores cujas inter-relações são representadas por arcos. Essa rede é conexa se existe, no mínimo, um caminho entre quaisquer pares de vértices. Caso não exista, dizemos que a rede é desconexa e cada subconjunto conexo é definido como um componente conexo. Interessante destacar que a componente conexa com maior número de vértices é, frequentemente, denominada na literatura como componente conexa gigante da rede. Usualmente, uma rede é dita direcionada quando um sentido de fluxo é estabelecido entre os vértices. Nesse tipo de rede direcionada, há dois graus associados a um vértice: o grau de entrada e o de saída. O grau de entrada de um vértice é dado como o total de arcos incidentes a este; o grau de saída corresponde ao total de arcos que partem de um vértice. Os graus de entrada e saída de um vértice são frequentemente utilizados como medida de centralidade de um vértice da rede. A seção seguinte faz uma descrição dos conceitos de centralidade em redes e apresenta a ideia geral de três métricas de centralidade.

Medidas de centralidade

As medidas de centralidade posicionam os pontos da rede a partir de graus que indicam as posições mais centrais na malha da rede, de acordo com a finalidade da abordagem. Existem diferentes tipos de centralidade nas redes sociais, e, em algumas delas, não são os pontos com mais ligações diretas que ocupam posições mais centrais, mas aqueles que, por sua posição estratégica, têm papel de destaque na informação e comunicação.

Marteleto (2001) apresenta três medidas que exemplificam esta abordagem. A centralidade da Informação é quando a posição estratégica do ponto permite receber informações de toda a malha; a centralidade de Proximidade garante posição mais central àquele ponto que está em menor distância dos outros pontos de ligação na malha, e a centralidade de Intermediação, que é

[...] o potencial daqueles que servem como intermediários. Calcula o quanto um ator atua como "ponte", facilitando o fluxo de informação em uma determinada rede. Um sujeito pode não ter muitos contatos, estabelecer elos fracos, mas ter uma importância fundamental na mediação das trocas. O papel de mediador traz em si a marca do poder de controlar as informações que circulam na rede e o trajeto que elas podem percorrer. (MARTELETO, 2001, p. 79)

Não obstante todas estas possibilidades, o objeto deste estudo vai se concentrar na abordagem que considera mais central aquele ponto com maior número de contatos diretos com outros pontos, a partir da informação de seu grau de entrada correspondente no grafo. Esta abordagem simples e direta atende perfeitamente ao objetivo de se buscarem publicações/autores mais citados, numa rede formada por relações diretas e perfeitamente quantificáveis, com o auxílio do PAJEK."
} 
relatórios não estão contabilizados na pesquisa, visto que não são artigos como os entendemos. Da mesma forma, há publicações que não apresentam autores, como é o caso de legislação especializada ou mesmo relatórios institucionais. Assim, não é possível encontrar palavras-chave nos referidos documentos. Com isso, temos algumas lacunas entre o número total de publicações e o número de artigos/autores/palavras-chave apropriados para a pesquisa.

Faz-se importante ressaltar que os autores do presente artigo encontraram dificuldades na catalogação das palavras-chave apresentadas pelos autores, visto que eram palavras diferentes, mas com igual significado, o que obrigou a reunião em palavras-chave padrão. Temos, como exemplos, 'formação de professores', 'formação de educadores', 'formação docente'.

Da mesma forma, encontramos diferentes maneiras de indicar a filiação institucional dos autores ao longo dos registros de artigos. Ora a instituição, às vezes o instituto ou faculdade, às vezes apenas as siglas, que se confundiam com instituições com mesma sigla. Esse tipo de dificuldade obrigou-nos a recorrer aos curricula vitae dos autores, na base LATTES, nem sempre atualizados.

Isso significa dizer que, do total dos documentos existentes na Ensaio, especialmente na primeira década, fomos levados a suprimir aqueles que não eram artigos, padronizar palavras-chave, adequar o vínculo institucional dos autores e acolher alguns poucos artigos sem vínculo institucional claro.

\section{Resultados obtidos}

\subsection{Autores}

\subsubsection{Autores da primeira década}

A primeira década da Revista Ensaio apresenta 271 artigos, com 276 autores. Quando listados no Quadro 2 abaixo, o Top Ten é:

A análise dos autores que publicaram na primeira década da Ensaio permite perceber uma prevalência de nomes ligados à Fundação Cesgranrio, mas com baixa incidência, se comparados ao conjunto. Tal fato é justificado considerando-se as dificuldades próprias de implantação de periódicos e de captação de trabalhos, antes do período de maturação e de conhecimento do periódico. 
Quadro 2 - Top ten de autores com relação a publicação de artigos na revista Ensaio - Primeira década

\begin{tabular}{|c|l|c|c|}
\hline \multicolumn{2}{|c}{ Autores } & $\begin{array}{c}\text { N de artigos publicados } \\
\text { na década }\end{array}$ & $\begin{array}{c}\text { Participação no } \\
\text { conjunto }\end{array}$ \\
\hline 1 & Jorge Ferreira da Silva & 7 & $2,58 \%$ \\
\hline 2 & Pedro Demo & 7 & $2,58 \%$ \\
\hline 3 & Carlos Alberto Serpa de Oliveira & 6 & $2,21 \%$ \\
\hline 4 & João Batista Araújo e Oliveira & 6 & $2,21 \%$ \\
\hline 5 & Thereza Penna Firme & 6 & $2,21 \%$ \\
\hline 6 & Candido Alberto Gomes & 5 & $1,84 \%$ \\
\hline 7 & Claudio Moura Castro & 5 & $1,84 \%$ \\
\hline 8 & Maria Cristina Leal & 5 & $1,84 \%$ \\
\hline 9 & Ligia Gomes Elliot & 4 & $1,48 \%$ \\
\hline 10 & Maria Judith Sucupira da Costa Lins & 4 & $1,48 \%$ \\
\hline 11 & Wagner Bandeira Andriola & 4 & $1,48 \%$ \\
\hline
\end{tabular}

Fonte: Elaborado pelos autores (2014).

\subsubsection{Autores da segunda década}

A segunda década da Revista Ensaio apresenta 349 artigos, com 498 autores. Quando listados no Quadro 3 abaixo, o Top Ten é:

A segunda década de Ensaio realça autores da Fundação Cesgranrio com baixa incidência, se comparados ao conjunto, e o surgimento de outros autores não contemplados na primeira década. A baixa participação dos autores

Quadro 3 - Top ten de autores com relação a publicação de artigos na revista Ensaio - Segunda década

\begin{tabular}{|c|l|c|c|}
\hline \multicolumn{2}{|c}{ Autores } & \multicolumn{1}{c|}{$\begin{array}{c}\text { N de artigos } \\
\text { publicados na década }\end{array}$} & $\begin{array}{c}\text { Participação no } \\
\text { conjunto }\end{array}$ \\
\hline 1 & Candido Alberto Gomes & 10 & $2,86 \%$ \\
\hline 2 & Ruben Klein & 10 & $2,86 \%$ \\
\hline 3 & Ana Carolina Letichevsky & 10 & $2,86 \%$ \\
\hline 4 & Flávia Obino Werle & 7 & $2,00 \%$ \\
\hline 5 & Alvaro Chrispino & 6 & $1,72 \%$ \\
\hline 6 & Nilma Santos Fontanive & 6 & $1,72 \%$ \\
\hline 7 & Thereza Penna Firme & 6 & $1,72 \%$ \\
\hline 8 & Donaldo Bello de Souza & 5 & $1,43 \%$ \\
\hline 9 & Heron Beresford & 5 & $1,43 \%$ \\
\hline 10 & Fátima Cunha Ferreira Pinto & 5 & $1,43 \%$ \\
\hline 11 & Jorge Adelino Costa & 5 & $1,43 \%$ \\
\hline 12 & Maria Judith Sucupira da Costa Lins & 5 & $1,43 \%$ \\
\hline 13 & Wagner Bandeira Andriola & 5 & $1,43 \%$ \\
\hline
\end{tabular}

Fonte: Elaborado pelos autores (2014). 
mais citados aponta para uma dispersão que indica grande participação de diferentes autores.

\subsubsection{Resultado geral dos autores}

Ambas as décadas da Revista Ensaio, quando reunidas, apresentam 620 artigos, com 705 autores. Quando listados no Quadro 4 abaixo, o Top Ten é:

A distribuição dos autores ao longo dos 20 anos de Ensaio indica grande dispersão, considerando-se que os autores mais citados aparecem com índice de participação baixo (2,26\% ou 14 artigos no universo de 620 artigos).

Outra variação é o número médio de autores por década. Na primeira década, contabilizaram-se 276 autores para 271 artigos, resultando em uma média de 1,01 autor/artigo. Na segunda década, esta relação se modifica, visto que passou a contar com 498 autores para 349 artigos, resultando na média de 1,43 autor/ artigo. A média para os vinte anos foi de 1,13 autor/artigo.

As Figuras 1 e 2 representam a rede de autores das duas décadas.

Quadro 4 - Top ten de autores com relação a publicação de artigos na revista Ensaio - Geral

\begin{tabular}{|c|l|c|c|}
\hline \multicolumn{2}{|c}{ Autores } & $\begin{array}{r}\text { N de artigos publicados } \\
\text { nas duas décadas }\end{array}$ & $\begin{array}{c}\text { Participação no } \\
\text { conjunto }\end{array}$ \\
\hline 1 & Candido Alberto Gomes & 14 & $2,26 \%$ \\
\hline 2 & Ruben Klein & 13 & $2,09 \%$ \\
\hline 3 & Thereza Penna Firme & 12 & $1,94 \%$ \\
\hline 4 & Ana Carolina Letichevsky & 11 & $1,77 \%$ \\
\hline 5 & Pedro Demo & 11 & $1,77 \%$ \\
\hline 6 & João Batista Araújo e Oliveira & 9 & $1,45 \%$ \\
\hline 7 & Maria Judith Sucupira da Costa Lins & 9 & $1,45 \%$ \\
\hline 8 & Wagner Bandeira Andriola & 9 & $1,45 \%$ \\
\hline 9 & Claudio de Moura Castro & 8 & $1,29 \%$ \\
\hline 10 & Alvaro Chrispino & 7 & $1,13 \%$ \\
\hline 11 & Fátima Cunha Ferreira Pinto & 7 & $1,13 \%$ \\
\hline 12 & Flávia Obino Corrêa Werle & 7 & $1,13 \%$ \\
\hline 13 & Jorge Ferreira da Silva & 7 & $1,13 \%$ \\
\hline 14 & Ligia Gomes Elliot & 7 & $1,13 \%$ \\
\hline 15 & Nilma Santos Fontanive & 7 & $1,13 \%$ \\
\hline
\end{tabular}

Fonte: Elaborado pelos autores (2014). 
Figura 1 - Relatório da partição dos vértices de acordo com grau de entrada

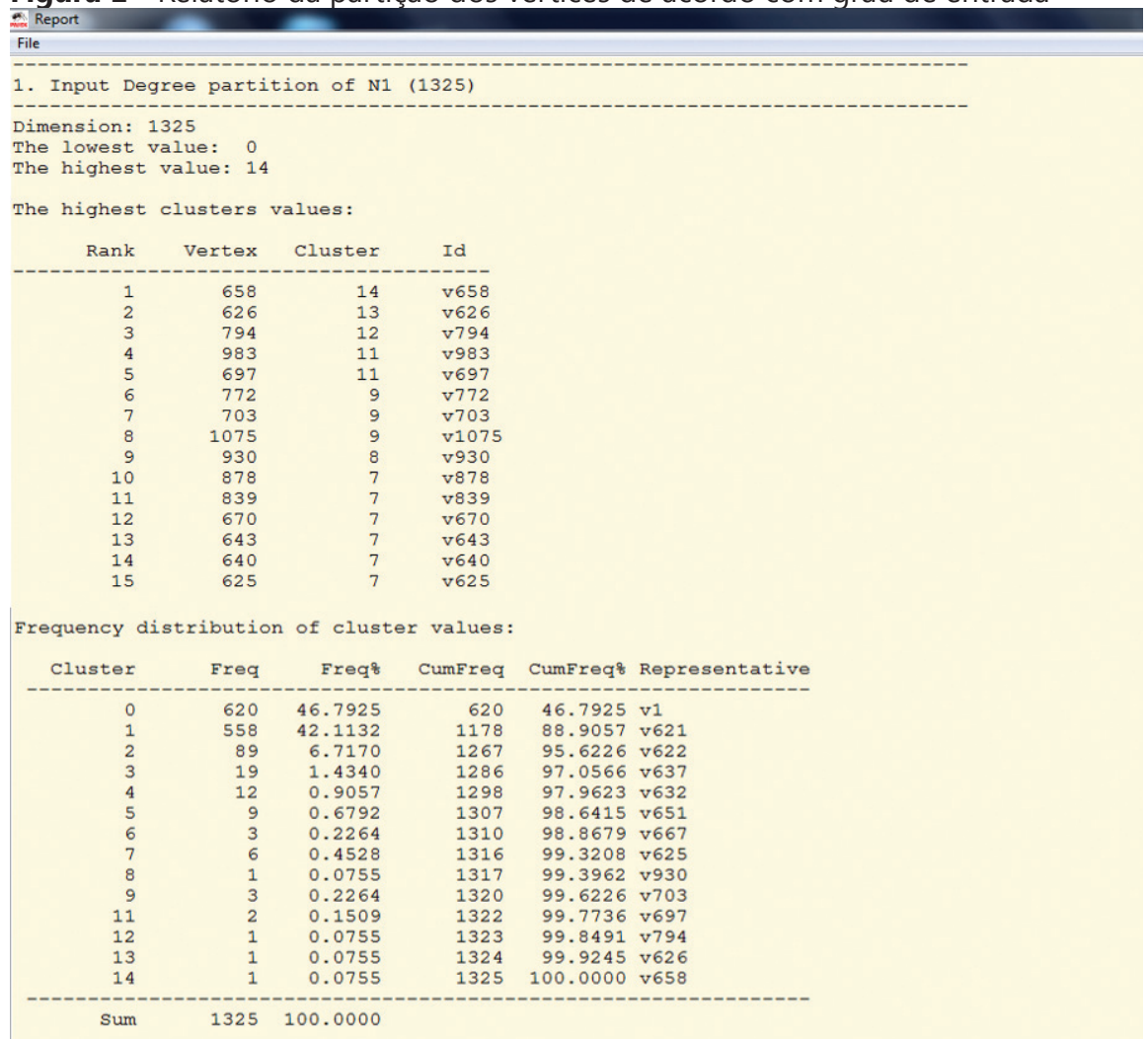

Fonte: Elaborado pelos autores (2014).

\subsection{Instituições a que se vinculam os autores}

\subsubsection{Instituições na primeira década}

Número total de vértices da Rede: 369

Total de 277 artigos, sendo 12 sem filiação. Portanto, temos 265 artigos considerados na rede e o total de 104 instituições.

A análise das instituições às quais estavam vinculados os autores dos artigos não oferece surpresa. As dificuldades naturais de implantação e implementação de periódico especializado solicita a participação de um núcleo de autores comprometidos com a viabilidade da Revista, com oferta de publicações mais sistemática, até que o periódico consiga captar autores e instituições diferentes. 


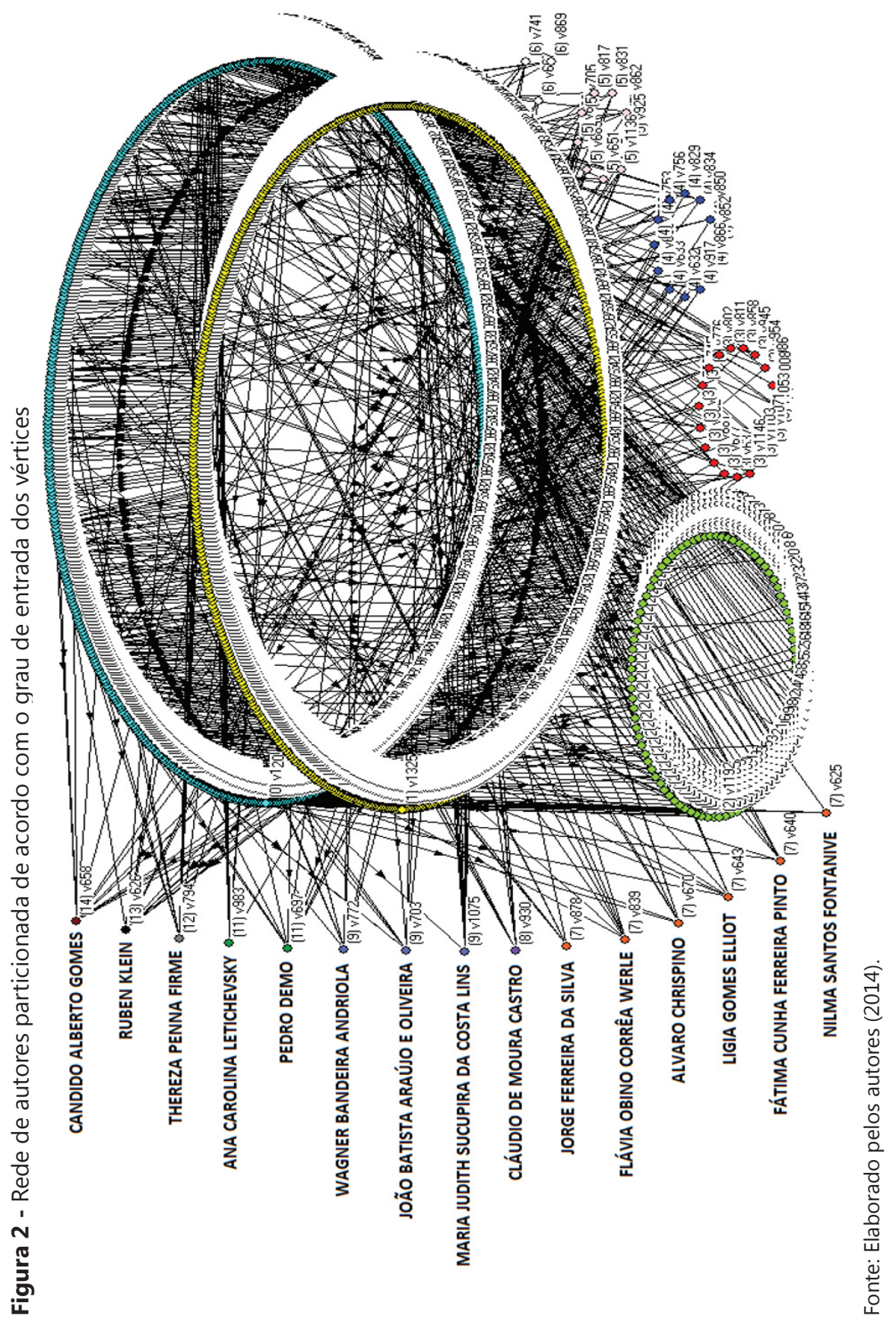


Por conta disso, era esperado a maior participação da instituição mantenedora da Ensaio - a Fundação Cesgranrio - no primeiro momento. Mesmo assim, a segunda maior participação é da UFRJ - Universidade Federal do Rio de Janeiro, com praticamente igual número de artigos.

No Top ten (Quadro 5), encontramos instituições sediadas no Rio de Janeiro, em Minas Gerais, no Ceará e em Brasília, além de uma estrangeira. Na primeira década da Ensaio, publicaram-se trabalhos com autores vinculados a instituições de 16 diferentes Estados do Brasil: Bahia, Ceará, Distrito Federal, Espírito Santo, Goiás, Mato Grosso, Minas Gerais, Paraíba, Paraná, Pernambuco, Piauí, Rio de Janeiro, Rio Grande do Norte, Rio Grande do Sul, Santa Catarina e São Paulo. Foram identificados trabalhos com autores vinculados a instituições estrangeiras sediadas na Argentina, na Espanha, nos Estados Unidos, no México, em Portugal e no Uruguai.

Quadro 5 - Top ten de instituições com relação a publicação de artigos na revista Ensaio - Primeira década

\begin{tabular}{|c|l|c|c|}
\hline \multicolumn{2}{|c}{ Instituições } & $\begin{array}{c}\text { N de artigos } \\
\text { publicados na } \\
\text { década }\end{array}$ & $\begin{array}{c}\text { Participação no } \\
\text { conjunto }\end{array}$ \\
\hline 1 & Fundação Cesgranrio & 37 & $13,9 \%$ \\
\hline 2 & UFRJ - Universidade Federal do Rio de Janeiro & 34 & $12,8 \%$ \\
\hline 3 & UERJ - Universidade do Estado do Rio de Janeiro & 20 & $7,55 \%$ \\
\hline 4 & UnB - Universidade de Brasília & 16 & $6,04 \%$ \\
\hline 5 & UFF - Universidade Federal Fluminense & 16 & $6,04 \%$ \\
\hline 6 & UFC - Universidade Federal do Ceará & 10 & $3,77 \%$ \\
\hline 7 & UCB - Universidade Católica de Brasília & 8 & $3,00 \%$ \\
\hline 8 & UFMG - Universidade Federal de Minas Gerais & 7 & $2,64 \%$ \\
\hline 9 & UNESA - Universidade Estácio de Sá & 7 & $2,64 \%$ \\
\hline 10 & $\begin{array}{l}\text { UNED/Madrid - Universidad Nacional de Edu- } \\
\text { cación a Distancia }\end{array}$ & 6 & $2,26 \%$ \\
\hline 11 & $\begin{array}{l}\text { PUC-Rio - Pontifícia Universidade Católica do } \\
\text { Rio de Janeiro }\end{array}$ & 6 & $2,26 \%$ \\
\hline 12 & Instituto Brasil Século XXI & 6 & $2,26 \%$ \\
\hline 13 & $\begin{array}{l}\text { PUC-MG - Pontifícia Universidade Católica de } \\
\text { Minas Gerais }\end{array}$ & 6 & $2,26 \%$ \\
\hline
\end{tabular}

Fonte: Elaborado pelos autores (2014).

\subsubsection{Instituições na segunda década}

Total de vértices da rede: 515, sendo o total de 349 artigos e o total de $\mathbf{1 6 6}$ Instituições. 
No que se refere à segunda década, há interessante mudança no quadro de instituições, como pode ser visto no Quadro 6. A UFRJ passa a ser aquela instituição cujos pesquisadores mais contribuem com artigos. Percebe-se o aparecimento de três universidades do Estado de São Paulo: a USP - Universidade de São Paulo, a Unicamp - Universidade Estadual de Campinas e a PUC-SP, sendo que a USP participa com o segundo maior contingente de artigos.

Quadro 6 - Top ten de instituições com relação a publicação de artigos na revista Ensaio - Segunda década

\begin{tabular}{|c|l|c|c|}
\hline \multicolumn{1}{|c}{ Instituiçães } & $\begin{array}{r}\text { N de artigos } \\
\text { publicados na } \\
\text { década }\end{array}$ & $\begin{array}{c}\text { Participação no } \\
\text { conjunto }\end{array}$ \\
\hline 1 & UFRJ - Universidade Federal do Rio de Janeiro & 50 & $14,33 \%$ \\
\hline 2 & USP - Universidade de São Paulo & 35 & $10,03 \%$ \\
\hline 3 & Fundação Cesgranrio & 32 & $9,17 \%$ \\
\hline 4 & $\begin{array}{l}\text { PUC-Rio - Pontifícia Universidade Católica do } \\
\text { Rio de Janeiro }\end{array}$ & 21 & $6,02 \%$ \\
\hline 5 & $\begin{array}{l}\text { PUC-SP - Pontifícia Universidade Católica de } \\
\text { São Paulo }\end{array}$ & 15 & $4,30 \%$ \\
\hline 6 & UMinho - Universidade do Minho & 15 & $4,30 \%$ \\
\hline 7 & Unicamp - Universidade Estadual de Campinas & 14 & $4,01 \%$ \\
\hline 8 & $\begin{array}{l}\text { UERJ - Universidade do Estado do Rio de } \\
\text { Janeiro }\end{array}$ & 13 & $3,72 \%$ \\
\hline 9 & UFC - Universidade Federal do Ceará & 11 & $3,15 \%$ \\
\hline 10 & $\begin{array}{l}\text { Unisinos - Universidade do Vale do Rio dos } \\
\text { Sinos }\end{array}$ & 10 & $2,86 \%$ \\
\hline
\end{tabular}

Fonte: Elaborado pelos autores (2014).

Na distribuição regional, identificamos Rio de Janeiro, São Paulo, Ceará e Rio Grande do Sul. Entram no grupo, São Paulo e Rio Grande do Sul, e deixam de frequentá-lo Minas Gerais e Distrito Federal. Identificamos ainda uma instituição estrangeira: a Universidade do Minho.

Na segunda década da Ensaio, publicaram-se trabalhos com autores vinculados a instituições de 17 diferentes Estados do Brasil: Bahia, Ceará, Distrito Federal, Espírito Santo, Goiás, Mato Grosso, Mato Grosso do Sul, Minas Gerais, Paraíba, Paraná, Pernambuco, Piauí, Rio de Janeiro, Rio Grande do Norte, Rio Grande do Sul, Santa Catarina e São Paulo. Foram identificados trabalhos com autores vinculados a instituições estrangeiras sediadas nos países: Alemanha, Argentina, Chile, Costa Rica, Cuba, Espanha, Estados Unidos, França, Itália, México, Portugal e Reino Unido. 


\subsubsection{Resultado geral das instituições}

Total de 277 artigos da Primeira Década, sendo 12 sem filiação. Portanto, foram considerados 265 artigos.

Total de 349 artigos da Segunda Década. Total de artigos é de 614 e o total de instituições é de 222, totalizando 836 vértices.

No conjunto resultante dos vinte anos de publicação, encontramos a UFRJ como instituição com maior número de publicações, seguida pela Cesgranrio e pela USP.

A lista das mais representativas no quesito vinculação de autores a uma Fundação indicou sete instituições públicas e duas confessionais.

Identifica-se a representação, no Top Ten (Quadro 7), de instituições sediadas no Rio de Janeiro, em São Paulo, no Ceará e no Distrito Federal.

Quadro 7 - Top ten de instituições com relação a publicação de artigos na revista Ensaio - Geral

\begin{tabular}{|c|l|c|c|}
\hline \multicolumn{2}{|c}{ Instituições } & $\begin{array}{c}\text { N de artigos pub- } \\
\text { licados nas duas } \\
\text { décadas }\end{array}$ & $\begin{array}{c}\text { Participação no } \\
\text { conjunto }\end{array}$ \\
\hline 1 & UFRJ - Universidade Federal do Rio de Janeiro & 84 & $13,69 \%$ \\
\hline 2 & Fundação Cesgranrio & 69 & $11,24 \%$ \\
\hline 3 & USP - Universidade de São Paulo & 40 & $6,51 \%$ \\
\hline 4 & $\begin{array}{l}\text { UERJ - Universidade do Estado do Rio de } \\
\text { Janeiro }\end{array}$ & 33 & $5,37 \%$ \\
\hline 5 & $\begin{array}{l}\text { PUC-Rio - Pontifícia Universidade Católica do } \\
\text { Rio de Janeiro }\end{array}$ & 27 & $4,40 \%$ \\
\hline 6 & UnB - Universidade de Brasília & 25 & $4,07 \%$ \\
\hline 7 & UFF - Universidade Federal Fluminense & 23 & $3,74 \%$ \\
\hline 8 & UFC - Universidade Federal do Ceará & 21 & $3,42 \%$ \\
\hline 9 & UCB - Universidade Católica de Brasília & 17 & $2,77 \%$ \\
\hline 10 & Unicamp - Universidade Estadual de Campinas & 17 & $2,77 \%$ \\
\hline
\end{tabular}

Fonte: Elaborado pelos autores (2014).

A Revista Ensaio vem atendendo a diversidade geográfica do Brasil, visto que publicou artigos oriundos de instituições instaladas em 17 Estados.

No que tange à participação de autores de instituições estrangeiras, a Revista vem publicando artigos de autores vinculados a instituições de 13 países diferentes: Alemanha, Argentina, Chile, Costa Rica, Cuba, Espanha, Estados Unidos, França, Itália, México, Portugal, Reino Unido e Uruguai. 
As Figuras 3 e 4 representam a rede de instituições das duas décadas.

\subsection{Palavras-chave}

\subsubsection{Palavras-chave - Primeira década}

Total de 277 artigos da Primeira Década, sendo 152 sem palavras-chave, pois não era obrigatório. Portanto, foram considerados 125 artigos e temos 449 palavras-chave.

Figura 3 - Relatório da partição dos vértices de acordo com grau de entrada da rede de instituições

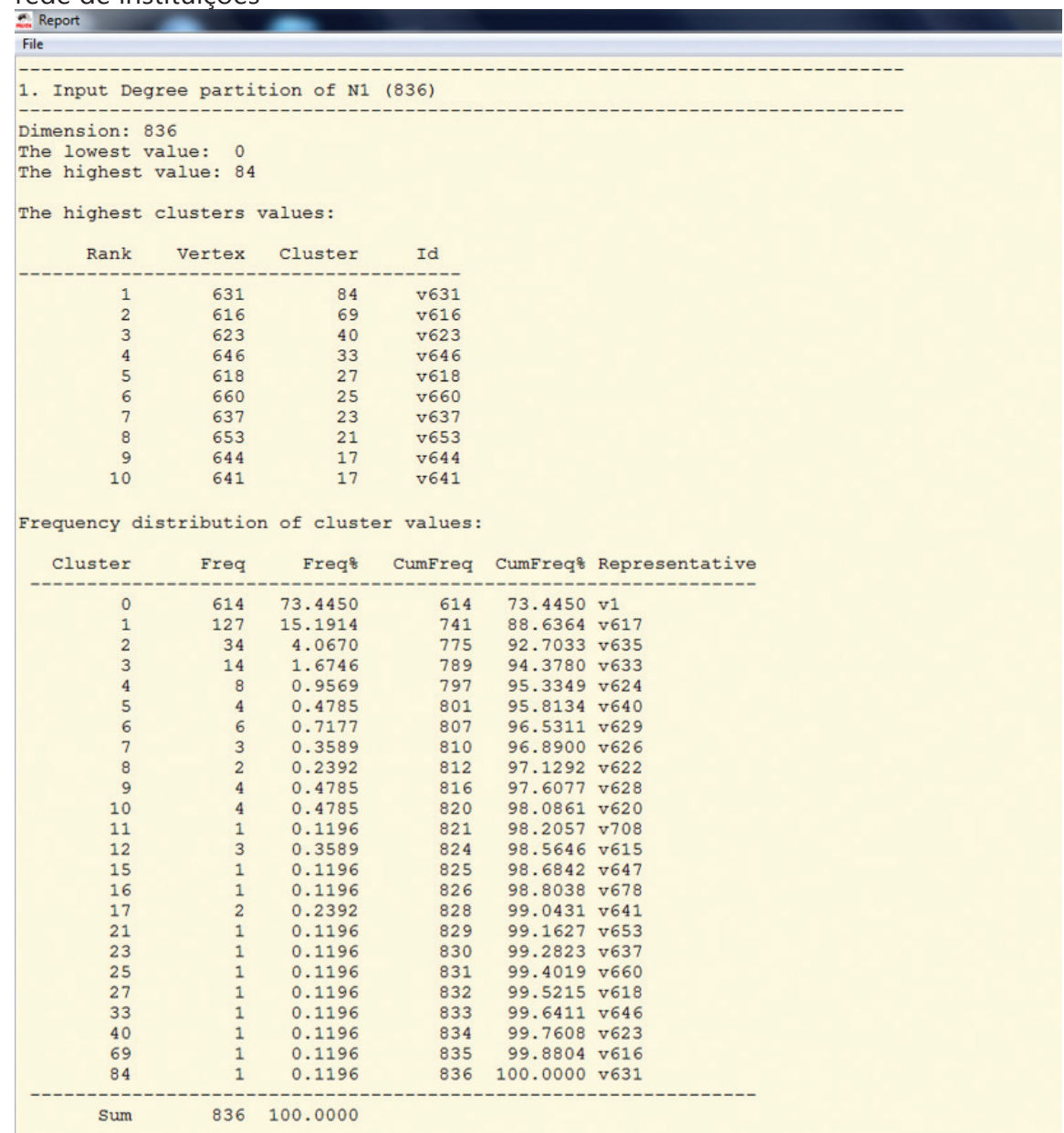

Fonte: Elaborado pelos autores (2014). 


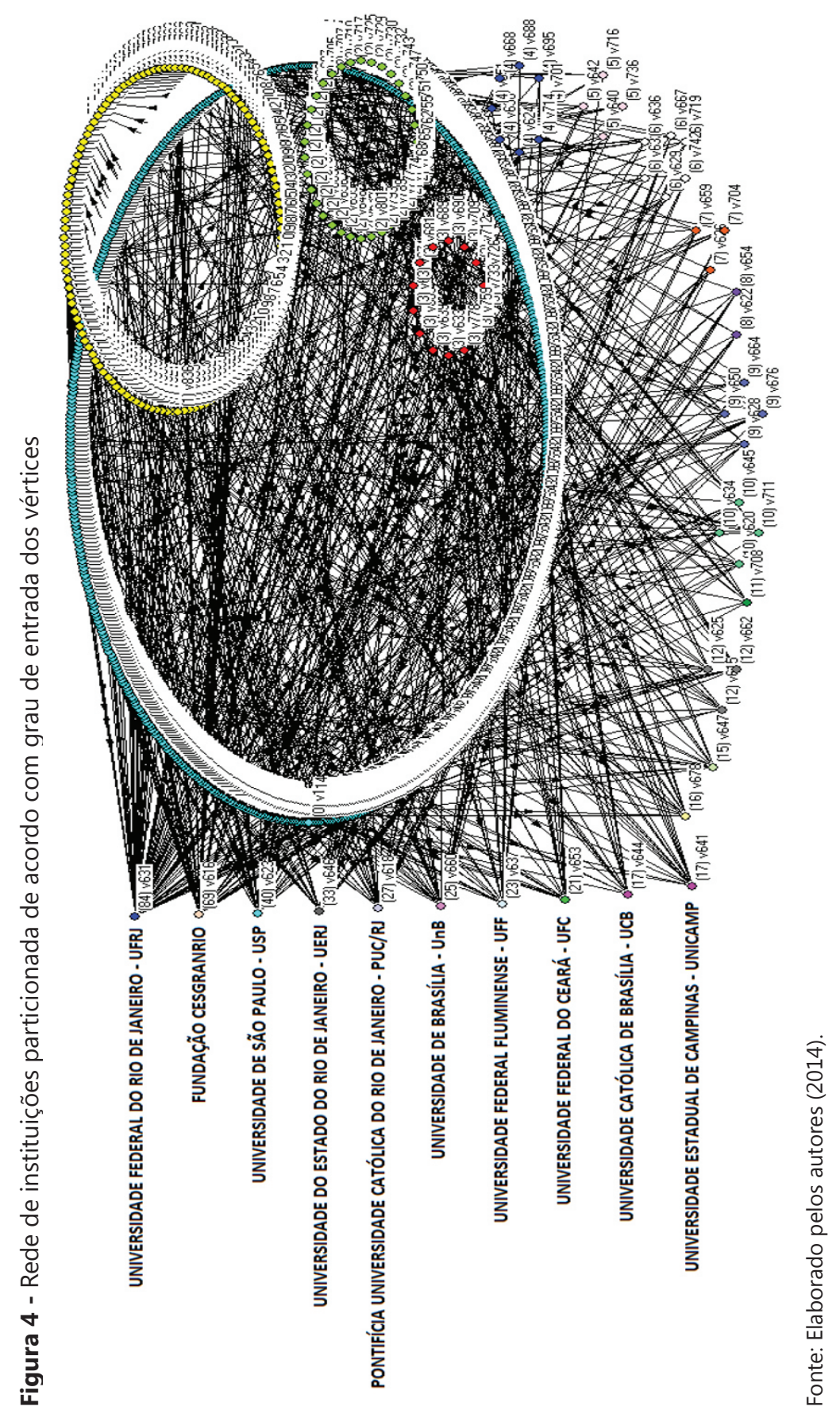


A palavra-chave pretende indicar a área mais geral ou mais específica de que trata o artigo. Em sua primeira década, considerando-se as dificuldades próprias de implementação do periódico e pelo tipo de publicação que veiculava, há trabalhos contidos na Ensaio que não continham as palavras-chave, por estas não serem obrigatórias à época. Logo, o universo considerado para análise na primeira década é reduzido, contando com apenas 125 artigos que indicavam 449 palavras-chave. Neste aspecto de análise, dos 277 artigos disponíveis, 152 não possuíam palavras-chave, o que representa uma perda de $54,87 \%$ da amostra.

A análise inicial já mostra que 'Avaliação', 'Educação'e 'Política Educacional' são as palavras-chave mais utilizadas pelos autores em seus trabalhos, com participações de 5,35\%, 3,79\% e 2,45\%, respectivamente. Os baixos valores parecem apontar para uma possível dispersão temática, se considerarmos que as palavras- chave representam os temas dos trabalhos publicados.

Na primeira década, as palavras-chave mais citadas aparecem em 21,44\% dos artigos, como pode ser verificado no Quadro 8 abaixo.

Quadro 8 - Top ten de palavras-chave relacionadas aos artigos publicados na revista Ensaio - Primeira década

\begin{tabular}{|c|l|c|c|}
\hline \multicolumn{2}{|c}{ Palavras-chave } & $\begin{array}{c}\text { N de participação em artigos } \\
\text { na década }\end{array}$ & Participação no conjunto \\
\hline 1 & Avaliação & 24 & $5,35 \%$ \\
\hline 2 & Educação & 17 & $3,79 \%$ \\
\hline 3 & Política educacional & 11 & $2,45 \%$ \\
\hline 4 & Avaliação Institucional & 7 & $1,56 \%$ \\
\hline 5 & Avaliação educacional & 6 & $1,37 \%$ \\
\hline 6 & Cultura & 6 & $1,37 \%$ \\
\hline 7 & Ensino superior & 5 & $1,11 \%$ \\
\hline 8 & Aprendizagem & 5 & $1,11 \%$ \\
\hline 9 & Ensino médio & 5 & $1,11 \%$ \\
\hline 10 & Gestão escolar & 5 & $1,11 \%$ \\
\hline 11 & Ensino fundamental & 5 & $1,11 \%$ \\
\hline
\end{tabular}

Fonte: Elaborado pelos autores (2014).

\subsubsection{Palavras-chave - Segunda década}

Total de 349 artigos da Segunda Década, sendo oito sem palavras-chave. Portanto, foram considerados 341 artigos e temos o total de 813 palavras-chave.

Na segunda década, o número de artigo saltou para 349 e apenas oito destes não possuíam palavras-chave, o que representou uma perda na amostra de 2,29\%. 
A análise qualitativa das palavras-chave aponta para a consolidação das áreas fins da Ensaio, a saber: Avaliação, Educação, Política(s) Pública(s) e Política Educacional, com participações de 6,27\%,3,69\%,3,69\% e 3,32\%, respectivamente. Os números parecem indicar que as palavras-chave mais citadas são mais representativas no universo de análise, dando especial participação àquelas que representam as áreas fins da Ensaio.

Na segunda década, as palavras-chave mais citadas aparecem em $27,54 \%$ dos artigos, como pode ser verificado no Quadro 9.

Quadro 9 - Top ten de palavras-chave relacionadas aos artigos publicados na revista Ensaio - Segunda década

\begin{tabular}{|c|l|c|c|}
\hline \multicolumn{2}{|c}{ Palavras-chave } & $\begin{array}{r}\text { N de participação em } \\
\text { artigos na década }\end{array}$ & Participação no conjunto \\
\hline 1 & Avaliação & 51 & $6,27 \%$ \\
\hline 2 & Educação & 30 & $3,69 \%$ \\
\hline 3 & Política(s) pública(s) & 30 & $3,69 \%$ \\
\hline 4 & Política educacional & 27 & $3,32 \%$ \\
\hline 5 & Educação superior & 23 & $2,83 \%$ \\
\hline 6 & $\begin{array}{l}\text { Formação de educadores/profes- } \\
\text { sores/docentes/em educação }\end{array}$ & 21 & $2,58 \%$ \\
\hline 7 & Ensino superior & 11 & $1,35 \%$ \\
\hline 8 & Gestão escolar & 11 & $1,35 \%$ \\
\hline 9 & Escola pública & 10 & $1,23 \% \mathrm{v}$ \\
\hline 10 & Aprendizagem & 10 & $1,23 \%$ \\
\hline
\end{tabular}

Fonte: Elaborado pelos autores (2014).

\subsubsection{Rede geral de palavras-chave}

Total de 277 artigos da Primeira Década, sendo 152 sem palavras-chave, pois não era obrigatório. Portanto, foram considerados 125 artigos.

Total de 349 artigos da Segunda Década, sendo oito sem palavras-chave. Portanto, foram considerados 341 artigos.

\section{Assim, temos 466 artigos e 1.131 palavras-chave.}

A análise das palavras-chave nas duas décadas traz agradáveis surpresas.

As áreas fins de Ensaio se sobressaem de forma relevante: Avaliação, Educação, Política Educacional e Política(s) Pública(s) encabeçam a lista e representam 
Quadro 10 - Top ten de palavras-chave relacionadas aos artigos publicados na revista Ensaio - Geral

\begin{tabular}{|c|l|c|c|}
\hline \multicolumn{2}{|c|}{ Palavras-Chave } & $\begin{array}{c}\text { N de participação } \\
\text { em artigos nas duas } \\
\text { décadas }\end{array}$ & $\begin{array}{c}\text { Participação no } \\
\text { conjunto }\end{array}$ \\
\hline 1 & Avaliação & 75 & $16,09 \%$ \\
\hline 2 & Educação & 47 & $10,9 \%$ \\
\hline 3 & Política educacional & 38 & $8,15 \%$ \\
\hline 4 & Política(s) pública(s) & 34 & $7,30 \%$ \\
\hline 5 & $\begin{array}{l}\text { Formação de educadores/professores/ } \\
\text { docentes/em educação }\end{array}$ & 25 & $5,36 \%$ \\
\hline 6 & Educação superior & 24 & $5,15 \%$ \\
\hline 7 & Ensino superior & 16 & $3,43 \%$ \\
\hline 8 & Gestão escolar & 16 & $3,43 \%$ \\
\hline 9 & Avaliação Institucional & 15 & $3,22 \%$ \\
\hline 10 & Aprendizagem & 15 & $3,22 \%$ \\
\hline
\end{tabular}

Fonte: Elaborado pelos autores (2014).

Figura 5 - Relatório da partição dos vértices de acordo com grau de entrada da rede de palavras-chave

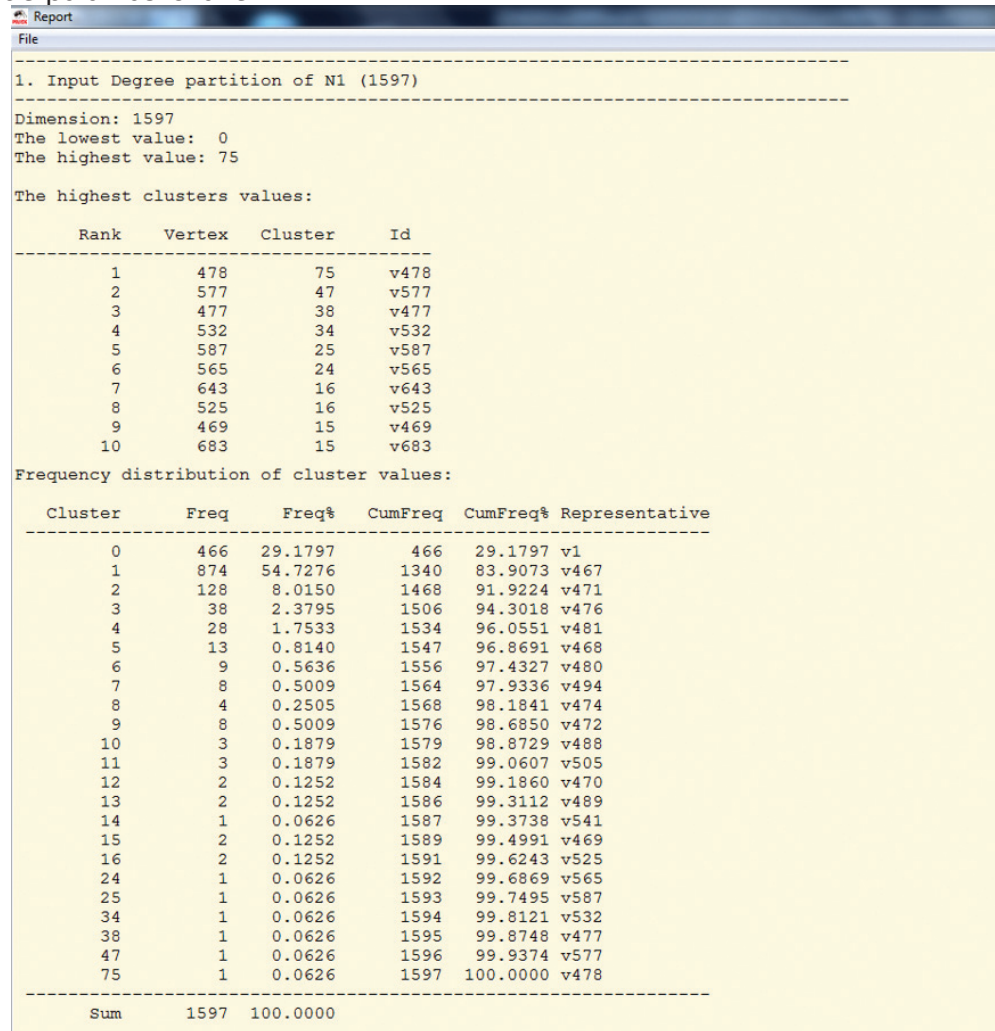

Fonte: Elaborado pelos autores (2014). 


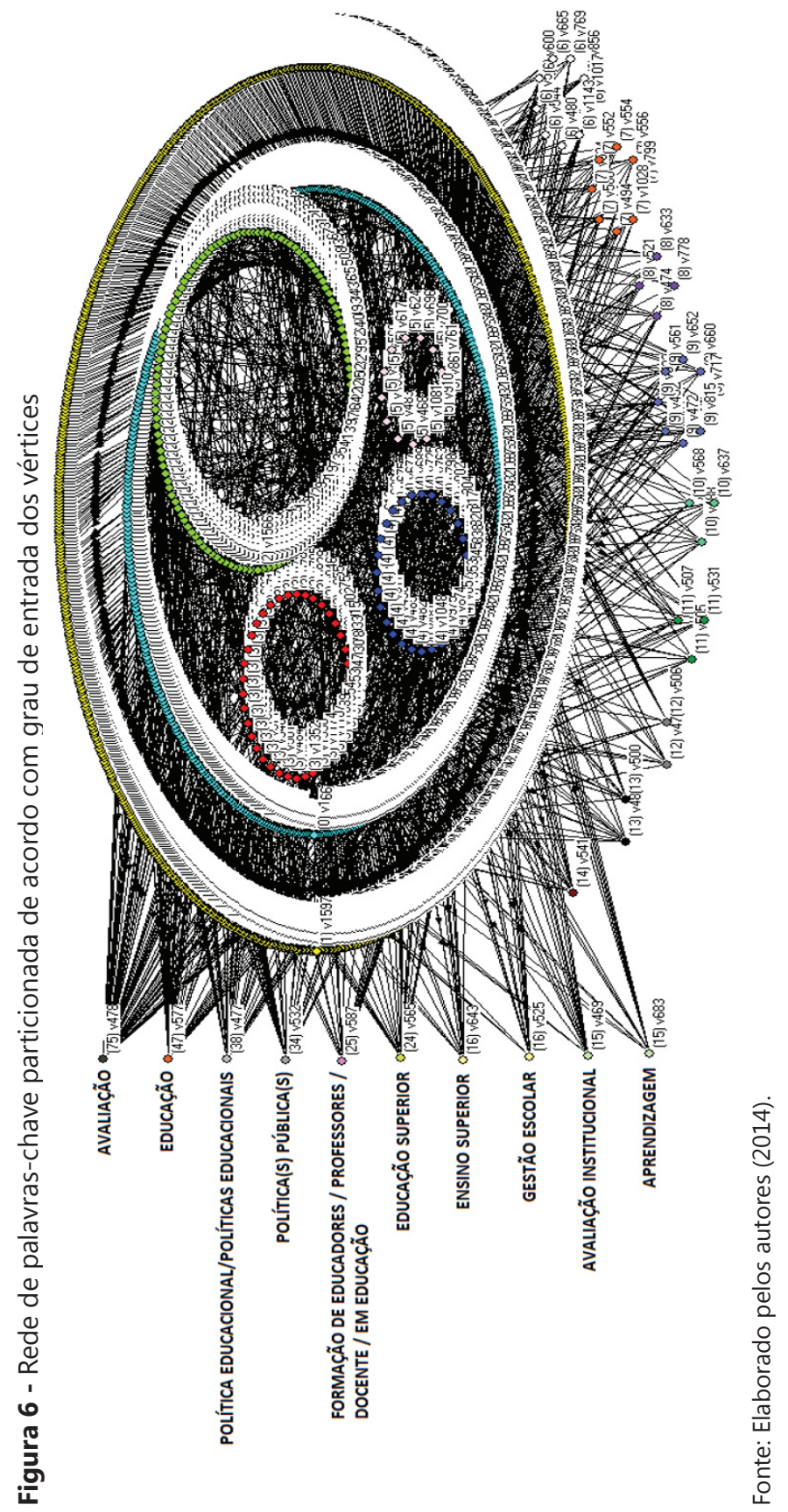


$16,09 \%, 10,9 \%, 8,15 \%$ e 7,30\%, respectivamente. Chama a atenção a participação da palavra-chave 'Avaliação', no conjunto: 16,09\%.

É possível perceber uma tendência de "vocacionar" a Revista, considerando-se que as palavras-chave mais citadas aparecem de forma mais representativa. Estas são citadas em 66, 25\% dos artigos, como pode ser visto no Quadro 10 abaixo.

As Figuras 5 e 6 representam a rede de palavras-chave das duas décadas.

\section{Conclusões}

Se for considerada a proposta contida no Editorial do número 1 da Ensaio, a Revista cumpriu seu papel. A análise das palavras-chave, tanto das duas décadas quanto da visão geral, demonstra que os campos prioritários propostos foram e são atendidos de forma relevante: Avaliação e Políticas Públicas em Educação. Da mesma forma, não ficam de fora da lista os temas relevantes que marcaram e marcam os debates sobre o grande campo da Educação.

A crítica apresentada por Tavares, Oliveira e Seiffert (2011) se esvanece, visto que as palavras-chave 'Educação Superior', 'Ensino Superior' e 'Avaliação Institucional', na lista dos Top Ten, aparecem em sexto, sétimo e nono lugares, respectivamente, entre as palavras-chave mais citadas pelos autores, registrando crescimento na primeira e na segunda décadas.

A representação dos diversos Estados e instituições é garantida na história das publicações da Ensaio. Dos 27 estados brasileiros, 17 publicam com regularidade na Ensaio, apesar de haver uma diferença importante no número de publicações oriundas de algumas regiões brasileiras.

A Ensaio vem alcançando importante espaço na literatura estrangeira especializada, visto que é procurada por autores de instituições estrangeiras, no esforço de divulgarem suas pesquisas. Na primeira década, registra-se a participação de autores de seis países, o que sobe para 12 países, na segunda década.

No que se refere às instituições às quais se vinculam os autores, a Ensaio oferece interessante quadro de análise. Estão presentes na lista, instituições públicas, privadas, confessionais e institucionais (Ministérios, Tribunais, Secretarias de Educação, Órgãos Representativos, Organismos Internacionais etc), nos diversos 
níveis (federal, estadual e municipal). O Top Ten deste tema apresenta as mais representativas instituições educacionais do Brasil, dando mostra que a Ensaio representa importante canal de divulgação de ideias, reflexões e pesquisas.

A presente pesquisa parece indicar que, ao longo dos vinte anos de circulação regular e ininterrupta, a Revista Ensaio: Avaliação e Políticas Públicas em Educação cumpriu o papel a que se propunha quando de seu lançamento, firmandose como veículo de divulgação de dados e ideias, reflexões e debates, no grande campo da Educação, oferecendo uma visão plural dos fenômenos educacionais nos diversos ângulos de análise, a saber: políticos, administrativos, econômicos, sociais, epistemológicos e axiológicos, especialmente.

Ao fim e ao cabo, a pesquisa permitiu apresentar importante perfil da evolução da Ensaio, bem como seu relevante papel na Educação Brasileira.

Podemos recomendar que, usando a mesma base de dados e a mesma metodologia de Redes Sociais, sejam desenvolvidas pesquisas que relacionem os autores mais citados, instituições e palavras-chave, bem como se utilize a medida de "Centralidade de Proximidade" para conhecer quais autores, instituições e palavras chaves - apesar de não serem os mais citados - fazem conexões ("pontes") entre grupos distintos de autores, instituições e palavras-chave.

Outra possibilidade, ampliando-se o banco de dados, é conhecer quais são as referências bibliográficas utilizadas nos artigos, identificando as referências mais citadas, suas escolas de pensamentos e abordagens, relacionando-as com as áreas identificadas pelas palavras-chave.

\section{Referências}

BARNES, J. A. Redes sociais e processo político. In: FELDMAN-BIANCO, B. (Org.). Antropologia das sociedades contemporâneas: métodos. São Paulo: Global, 1987. p. 159-193.

CHRISPINO, A. et al. A área CTS no Brasil vista como rede social: onde aprendemos? Ciência \& Educação, Bauru, v. 19, p. 455-479, 2013.

CHRISPINO, A.; LIMA, L. S.; ALBUQUERQUE, M. B. Vendo CTS como rede: as publicações mais prestigiadas no Brasil. Enseñanza de las Ciencias, Barcelona, v. extra, p. 919-923, 2013. 
ELIAS, N. A sociedade dos indivíduos. Rio de Janeiro: Jorge Zahar, 1994.

FARIA, C. A. P. Implementação: ainda o "elo perdido" da Análise de Políticas Públicas no Brasil? In: FARIA, C. A. P. (Org.) Implementação de políticas públicas: teoria e prática. Belo Horizonte: PUC Minas, 2012.

MARTELETO, R. M. Análise de redes sociais: aplicação nos estudos de transferência da informação. Ciência da Informação, Brasília, v. 30, n. 1, p. 71-81, 2001.

OLIVEIRA, C. A. S. Editorial. Ensaio: Avaliação e Políticas Públicas em Educação, Rio de Janeiro, v. 1, n. 1, p. 1-4, 1993.

SCOTT, J. Social network analysis: a handbook. 2004. Disponível em: $<$ http:// www.analytictech.com/mb119/tableof.htm>. Acesso em: 8 dez. 2010.

TAVARES, M. G. M.; OLIVEIRA, M. A. A.; SEIFFERT, O. M. L. B. Avaliação da educação superior na revista Ensaio: Avaliação e Políticas Públicas em Educação: ênfases e tendências. Ensaio: Avaliação e Políticas Públicas em Educação, Rio de Janeiro, v. 19, n. 71, p. 233-258, 2011. Disponível em: <http://www.scielo.br/ scielo.php?script=sci_arttext\&pid=S0104-40362011000300002\&lng=pt\&nrm=iso $>$. Acesso em: 29 ago. 2014. http://dx.doi.org/10.1590/S0104-40362011000300002

\section{Twentieth anniversary of Ensaio Journal analyzed through Social Networks \\ Abstract}

The purpose of this work is to analyze the twenty-year history of Ensaio Journal using the approach of Social Networks, more specifically to analyze it by the application of the Pajek Software. To this end, all the articles published in the eighty numbers of the Journal in this period were listed, also registering the authors, the keywords used in each paper, and the authors' institutions. The data collected was analyzed in two ways to improve the understanding of how the Journal has evolved over time. In one way, the analysis was made with all the data from this work. In the other, the analysis compared and contrasted the data by dividing them within two separate decades. This work listed a total of 620 articles, 1325 authors, and 1131 keywords found. The first analysis resulted in Top Ten lists, indicating the authors with the largest number of papers published, the institutions most associated with the Journal, and the most frequently used keywords throughout the twenty years of the Journal. The second analysis resulted 
in the comparison of the Top Ten lists of each decade, showing that Ensaio fulfills its mission as defined at the moment of its creation.

Keywords: Ensaio Journal. Scientific publishing. Social networks.

\section{Los Veinte Años de la Revista Ensaio analizados por medio de Redes Sociales \\ Resumen}

La propuesta de este trabajo es presentar los 20 años de historia de la revista Ensaio utilizando el abordaje de Redes Sociales, especificamente a partir de la aplicación del software PAJEK. Para alcanzar tal objetivo, fueron listados todos los artículos publicados en los 80 números que componen el periodo, registrando autor(es), institución a la que se vincula el autor y palabras clave. Para una mejor comprensión, además del análisis completo de los 20 años, se usó como categoría de análisis la primera y la segunda décadas, permitiendo una visión evolutiva. Se listaron 620 artículos, 1325 autores y 1131 palabras clave. El primer análisis de los datos resultó en el Top Ten de las listas, los autores que más publicaron, las instituciones más representadas y las palabras clave más utilizadas por década. En total, se demostró que Ensaio cumple su misión conforme la definición en el momento de su creación.

Palabras-clave: Revista Ensaio. Edición científica. Redes sociales.

\section{Informações dos autores}

Alvaro Chrispino: editor Associado da Ensaio. Doutor em Educação pela UFRJ, professor dos Programas de Pós-graduação do CEFET/RJ. Contato: alvaro. chrispino@gmail.com

Marcia Bengio Albuquerque: graduada em Matemática. Doutoranda do PPCTEPrograma de Pós-graduação em Ciência, Tecnologia e Educação do CEFET/RJ.

Patricia Borges Coutinho da Silva: graduada em Biologia, mestranda do PPCTEPrograma de Pós-graduação em Ciência, Tecnologia e Educação do CEFET/RJ. 